\title{
Comparison of Distal Transradial in the Anatomical Snuffbox versus Conventional Transradial Access for Coronary Angiography and Intervention-An Experience in 100 cases
}

MD. RASUL AMIN ${ }^{1}$, CHAYAN KUMAR SINGHA ${ }^{1}$, SAJAL KRISNA BANERJEE ${ }^{1}$, HARISUL HOQUE ${ }^{1}$, SM EAR E MAHABUB ${ }^{1}$, MOSTASHIRUL HOQUE ${ }^{1}$, ESHITA BISWAS ${ }^{2}$

${ }^{1}$ Department of Cardiology, Bangabandhu Sheikh Mujib Medical University (BSMMU), Dhaka, ${ }^{2}$ Department of Medicine, Dhaka National Medical College and Hospital, Dhaka.

Address of Correspondence: Dr. Chayan Kumar Singha, Medical Officer, Department of Cardiology, Bangabandhu Sheikh Mujib Medical University (BSMMU), Dhaka. E-mail: singhachayan@yahoo.com.

\begin{abstract}
:
Background: Distal transradial access in the anatomical snuffbox has advantages over standard proximal access in terms of patient and operator comfort levels and risk of ischemia. Radial artery preservation could be a relevant issue in patients requiring multiple radial artery procedures and coronary bypass with the use of a radial graft or construction of Arterio-Venous fistula in patient of chronic kidney disease. One relevant drawback is the challenging puncture of a small and weak artery, with a steeper learning curve.
\end{abstract}

Objectives:This study sought to compare the feasibility, safety and complications of coronary angiogram and intervention betweenthe distal transradial in the anatomical snuffbox and conventional transradial access.

Methods: In this cross sectional studya total of 100 patients were assigned to perform coronary angiogram or intervention through conventional transradial accessand distal transradial in the anatomical snuffboxfrom November 2017 to April 2018 in theDepartment of Cardiology, Bangabandhu Sheikh Mujib Medical University (BSMMU). We divided the total patient in two groups, with 50 patientsin each group. All of them had normal pulse in theirradial and dorsal radial artery. One group was subjected toconventional right transradial accessand another to rightdistal transradial in the anatomical snuffbox.Demographic features \&complications were recorded.

Results: The overall procedural success was $98 \%$ which was greater than expected in our early clinical experience for distal transradial access with 48 successful accesses out of 50 patients and for conventional radial approach it was also $98 \%$. There was failure to access of distal radial artery in two casesthat may be due to hypoplastic/vasospastic distal radial artery and for conventional radial artery radial artery spasm was the cause. Patients of conventional radial access had more spasm, hematoma, numbness and hospital stay $(p<0.001)$ than distal radial access. Considering all, it may be said thatdistal transradialaccess was very much effective and safe as there was less spasm, more comfortable to the patient, no hand ischemia, hematoma, numbness, and early hospital discharge.

Conclusion: Distal transradial access in the anatomical snuffbox for coronary angiogram and intervention is abetter alternative, safe and feasible option to conventional transradial access for both patients and operators.

Key Words: Conventional transradial access, distal transradial access, Anatomical snuffbox, Coronary angiography and Intervention.

University Heart Journal 2017; 13(2): 40-45

Introduction:

Cardiac catheterization has continually evolved since the first procedure in 1929 (1). Improvement in technology and understanding the anatomic features of the vascular system, have lead to new insights in coronary angiography procedures. With regard to arterial access sites, much research has been devoted to determine which access site is best suited for particular patients and circumstances. In spite of the ease of access of femoral artery for coronary angiography, vessel related 
complications and bleeding have given rise to increased morbidity, mortality, and hospital stay, particularly when anticoagulation and antiplatelet therapies are administered. ${ }^{2,3}$ The femoral approach has been compared with radial approach for both coronary angiography and interventional procedures in multiple randomized and observational studies. Increased safety and patient comfort with reduction of bleeding complications and immediate post procedural mobilization were found as the major advantages of radial access. $^{4,5}$ On the basis of the results of these randomized studies, transradial access is considered as the default technique for coronary access. 6,7 Most operators prefer the right radial artery, as they work on the right side of the patients. However, right radial artery occlusion, underdeveloped right radial artery, extreme tortuosity, sclerosis, calcifications, arteria lusoria, past or future use of right radial artery as free arterial graft make the operators choose the left radial artery. ${ }^{8}$ From the other hand, left radial access can be somewhat difficult for the operator as he should bend over the patient to introduce the sheath to the left radial artery. This unpleasant position could make the catheterization procedure inconvenient and perhaps crossover to another artery access site. An alternative way to have a comfortable position for both the patient and the operator is access the distal radial artery located in the anatomical snuffbox or "fossa radialis" on the dorsal side of the hand. Anatomical snuffbox (AS) is a depressed space located in the radial part of the wrist. It shows up when the thumb is extended. It is surrounded laterally by the tendons of abductor pollicis longus and extensor pollicis brevis muscles and medially by the tendon of extensor pollicis longus muscle. The base and the lateral side of this triangular structure are formed by the distal retinaculum of extensor muscles and attachment of the tendons of extensor pollicis longus and extensor pollicis brevis muscles respectively (Fig. 1). The distal radius, scaphoid, trapezium and the base of the first metacarpal bone form the base of this triangular area. ${ }^{9}$ The distal part of the radial artery passes in a deep fashion through AS. Distally it continues as the deep palmar branch of the radial artery and joins the distal part of the ulnar artery, thus forming the deep palmar arch of the hand (Fig. 2). The distinctive feature of this arterial segment is its location distally to the superficial palmar branch of radial artery that joins the superficial palmar arch. There arecollateral vessels communicating between the palmar arches. If any occlusion in the AS site occurs, tissue ischemia is prevented because of the maintenance of antegrade flow through the superficial palmar arch and the communicating collaterals. ${ }^{10}$ In consideration of these anatomic and physiological features we aimed to describe our experience regarding feasibility, safety and complications with this new access site distal transradial to conventional radial access for coronary angiogram and intervention.

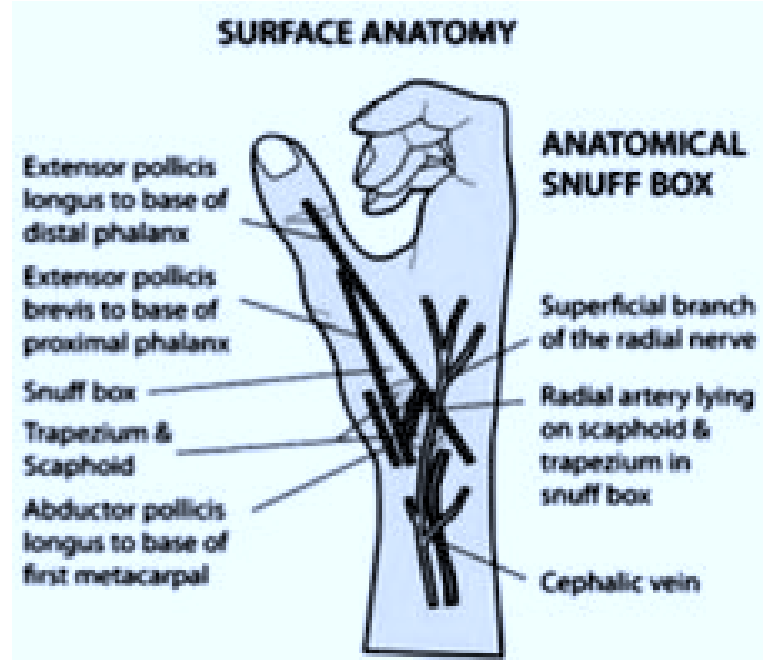

Fig.-1: Surface anatomy of anatomical snuff box.

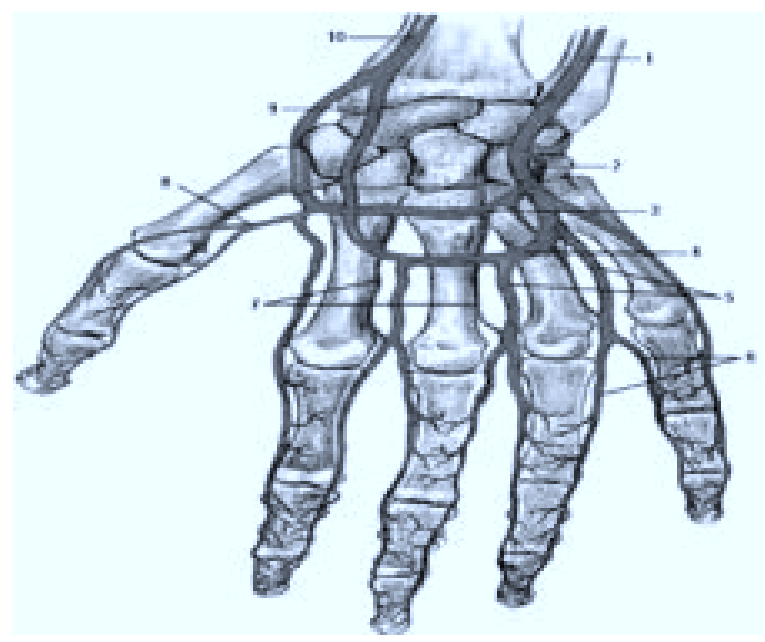

Fig.-2: Blood vessels of the distal forearm and hand. 1-Ulnar artery; 2, 3 - deep palmar branch of radial artery; 4, 9 - superficial palmar arch; 5 - digital arteries; 8 - artery of the thumb; 10 - radial artery

\section{Methods:}

It was a cross sectional study that was carried out in the department of cardiology of BSMMU, Dhaka, Bangladesh from November 2016 to April 2017. Meticulous history, detailed clinical examination and necessary investigations were done. Considering the 


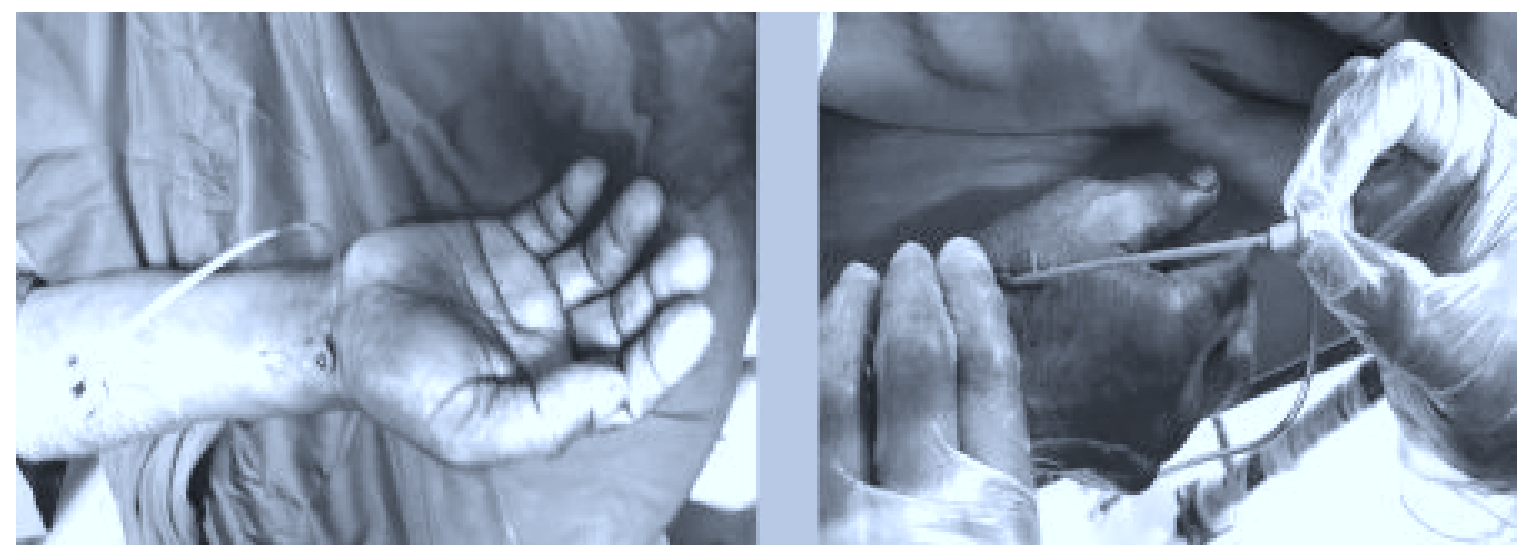

Fig.-3:Vascular accesssheath in the right radial artery and removal of thesheath from right dorsal radial artery.

inclusion and exclusion criteria, we included a total of 100 patients who underwent coronary angiogram and intervention. We divided the total patients into two groups each having 50 patients. One group underwent conventional transradial access (CTRA) and other group underwent distal radial (DTRA) access. All patients had a normal arterial pulse in their radial and AS area. In the catheterization laboratory after disinfection with povidone iodine the patient's right hand was kept in the right side of the body on the hand support system in the semi-prone position close to the body curling the thumb with other four fingers, thus making the fossa radialis more prominent.The operator was positioned in the right side of the patients preparing for right distal or conventional right radial artery puncture.

After injecting $2 \mathrm{~mL}$ of $2 \%$ lignocaine over a single area ofrightAS or $2 \mathrm{~cm}$ proximal to styloid process for conventional radialaccess, a 21-gauge open needle was introduced with a 30 to 45 degree angle. Successful puncture was followed by an insertion of 0.018 -inch straight guide wire with asoft, flexible proximal part and a rigid distal part. Then a 6 French radial hydrophilic sheathfor DRA and 6 Frenchradial hydrophilic sheath was introduced into the radial artery and a cocktail of 2500 units of unfractionated heparin, $100 \mathrm{mcg}$ of nitrate and 1 $\mathrm{ml}(2.5 \mathrm{mg})$ of verapamil was administered to all patients to prevent arterial spasm. In case of interventions being performed, heparin dose was adequately adjusted. After flushing of the radial sheath, the operator on the right side of the patient would begin the transradial coronary angiography or intervention. Most frequently used catheters were Tiger, Judkins or XB according to need of the patients.Advancement of the catheters was achieved by 0.032 -inch J-tipped wire. At the termination of the procedure the radial sheath was pulled out and early hemostasis was obtained by compression with the thumb of the assistant for approximately $15 \mathrm{~min}$ then a slightly compressive bandage with gauze was applied for $3 \mathrm{~h}$ over the access site for complete hemostasis. The radial arterial pulse at the forearm and at AS was checked by palpation after the procedure and at discharge day.

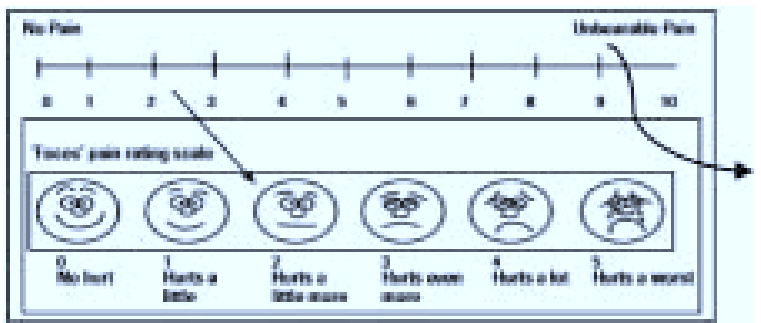

Fig.-4: Visual analog scale- Pain describing visual scale during distal transradial and conventional transradial interventional procedure. (Straight arrowDTRA, curved arrow-CTRA).

\section{Result:}

We had 100 patients assigned to our study from November 2017 to April 2018 who had normal pulse in their forearm and AS. Demographic and procedural features are shown in tables 1 and 2. There was a population group with a mean age of 50years and male predominance of $70 \%$. Hypertension, smoking \& diabetes mellitus were the most frequent risk factors for cardiovascular disease, with rates of $80 \%, 65 \%$ \& $60 \%$ respectively. Sixty (60) patients were admitted to our unit of BSMMU with acute coronary syndrome. Twelve (12) of them had anterior ST elevation myocardial infarction (STEMI). Inferior STEMI was diagnosed in 18 patients. The other 25 patients presented with nonSTEMI, and the last five (5)with unstable angina. In total we had 60 angioplasty procedures, among which 10 were 
primary coronary interventions. The left anterior descending artery was the most frequently stented artery (30). Approximately $20 \%$ and $10 \%$ patientsunderwent angioplasty with stenting in the right coronary artery and the left circumflex artery respectively. Both distal radial and conventional radial artery access was successful in $98 \%$ patients. Two patients from each group were shifted into transfemoral access due to weak pulse and vasospasm. Mean time to puncture of artery was $1.2 \mathrm{~min}$ andmean fluoroscopy time was assessed as $9.6 \mathrm{~min}$ in both route. Catheters used for diagnostic and interventional procedures were Tiger, XB and sometimes Judkins. Patients felt less discomfort or pain at access sites during coronary angiography or intervention through DTRA compared to CTRA. None of the patients experienced any radial artery occlusion, hematoma, numbness through DTRA but hematoma, numbness, spasm and radial arterial occlusion occurred in CTRA in consecutive of 2, 2, 2 and 2 patients. Twenty patients were discharged on the same day after their coronary angiography showed mild atherosclerotic lesions. The mean hospital stay was 2 and 3 days for the patients undergoing angioplastywith DTRA and CTRA respectively.

Table-I

Demographic characteristics of study population

\begin{tabular}{lc}
\hline Demographic parameters & $\begin{array}{c}\text { Mean } \pm \text { SD } \\
(\text { min.-max. })(\mathrm{n}=100)\end{array}$ \\
\hline Age & $50 \pm 10(30-80)$ \\
Height $(\mathrm{cm})$ & $160.72 \pm 6.226(145-187)$ \\
Weight $(\mathrm{kg})$ & $70 \pm 10.024(55-100)$ \\
Hospital stay (days) & $2 \pm 1.5(0-8)(\mathrm{DTRA})$ \\
& $3 \pm 2.5(0.5-12)(\mathrm{CTRA})$ \\
LVEF & $0.52 \pm 0.083(0.37-0.60)$ \\
Male & $70(70 \%)$ \\
Female & $30(30 \%)$ \\
DM & $60(70 \%)$ \\
HTN & $80(80 \%)$ \\
Smoking & $65(65 \%)$ \\
AF & $4(4 \%)$ \\
SIHD & $40(40 \%)$ \\
\hline
\end{tabular}

New onset CAD 60 (60\%) AF - atrial fibrillation; CAD - coronary artery disease; cm - centimeters; DM - diabetes mellitus; HTN - hypertension; kg - kilogram; LVEF - left ventricle ejection fraction; min - minimal; max maximal; $\mathrm{n}$ - number of patients; SIHD- stable ischemic heart disease; SD - standard deviation.
Table-II

Procedural characteristics of patients undergoing conventional \& distal transradial coronary angiography and interventions

Procedural featuresn $=100$

Radialsheath (6 French)

$98(98 \%)$

Judkins catheters

$20(20 \%)$

Tiger catheters

$60(60 \%)$

XB catheters

$50(50 \%)$

Acute coronary Syndrome

$60(60 \%)$

Anterior STEMI

$12(12 \%)$

Inferior STEMI

$18(18 \%)$

Non-STEMI

$25(25 \%)$

UA

$5(5 \%)$

Angioplasty

$60(60 \%)$

Primary coronary intervention

$10(10 \%)$

Right coronary intervention

$20(20 \%)$

Left anterior descending intervention

$30(30 \%)$

Left circumflex artery intervention

$10(10 \%)$

Crossover to femoral artery (In each group) 2(2\%)

Radial artery occlusion ( DTRA)

(CTRA)

0

Hematoma (DTRA)

$2(2 \%)$

(CTRA)

0

Numbness ( DTRA)

$2(2 \%)$

0

(CTRA)

Arm movement disability

$2(2 \%)$

0

Mean \pm SD

Artery puncture time (min) $1.2 \pm 0.94$

Fluoroscopy time $(\mathrm{min}) 9.6 \pm 7.1(1.2-40.1)$

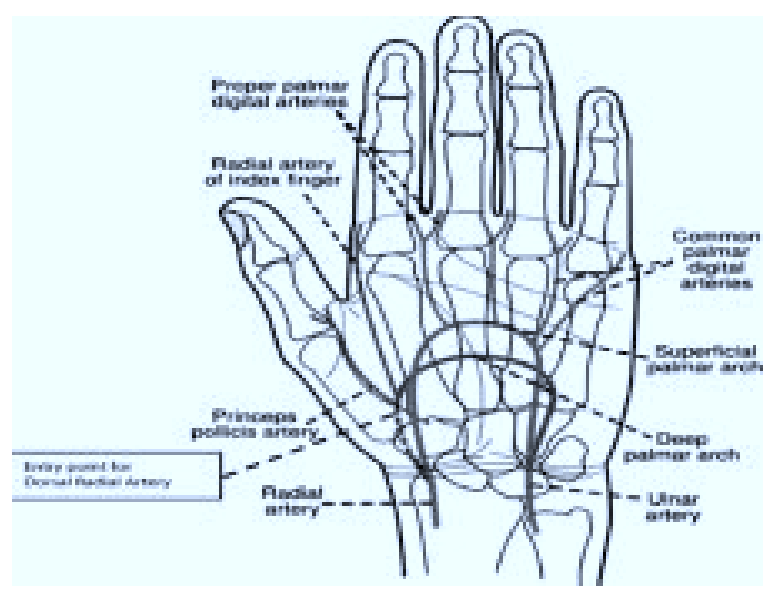

Fig.-5: Puncture sitein the anatomical snuffbox area which is in between the collaterals of superficial and deep palmar arch. 


\section{Discussion:}

Comparison between radial vs. femoral access, right radial vs.left radialfor coronary interventional procedures have been done in national and international context previously but comparison of distal radial vs. conventional radial access for coronary procedures havenot been yet done in our country.

Our first and new experience with an approach through theright distal radial artery for coronary angiography and intervention demonstrates its feasibility as a safe access site because of less complications and more comfortibility to the patient. Though advancement of the catheters and anchoring at the coronary ostium is easier through the left sided approach, ${ }^{11}$ but as most of the operators are used to do right sided puncture, so right radial and right distal radial artery was chosen. Butbending of the operators over the patient toward his or her left arm makes the procedure inconvenient and disturbing, especially in obese and female patients. So, the rightsided approach for conventional radialand distal radial artery access in AS provides advantages for both the patients and the operators. At the start of vascular access of CTRA right hand was kept along theside of the body in supine position with fingers and wrist kept in dorsiflexed state with a support but during DTRA patient's hand was kept in semiprone position without any support thus avoiding the possible discomfort that may arise from prolonged procedure.After successful puncture a hydrophilic radial sheath of 6 Frenchwas introduced in all patients. We did not experience any resistance advancing the guidewires and the 6 French catheters through the sheath in both accesses meaning that the angle of the introduced sheath was coaxial with the radial artery. One of the encouraging features of DTRA was its ease of access especially in patients with acute coronary syndrome where it provided more confidence toward contemplating the intervention. In total, the score of visual analog scale of pain was low (Fig. 4) in DTRA in comparison to CTRA.

Kaledin et al. ${ }^{12}$ showed that DTRA access is a safer option compared to CTRA regarding the possibility of hand ischemia. They found that the preservation of the palmer archduring DTRA is responsible for this advantage over CTRA. Our study also supports their findings where $2 \%$ patients undergoing CTRA developed hand ischemia but none of the DTRA group had this complication. Several studies involving CTRA showedthat post-catheterization radial artery occlusion is the most common complication during the transradial coronary angiography, and it is reported to be $1 \%-10 \%$ in patients undergoing catheterization (15) but we experience 2 cases by CTRA and none from DTRA. Relatively high rates of this complication in CTRA encouraged us to utilize the DTRA as the access site.As the radial portion in AS is a segment distal from the origin of the superficial palmar arch so antegrade blood flow through the superficial palmar arch would still continue without any dysregulation. ${ }^{12}$ In addition, multiple collateral vessels communicating between the superficial and deep palmar arches act as salvage artery vessels if any occlusion occurred in the hand artery circulation (Fig. 5). ${ }^{16}$ From this anatomic and physiological evaluation of the palmar arches, DTRA can be expected to avoid any peri or post procedural vascular occlusion. This is also a very useful way to preserve the radial artery for future graft in $\mathrm{CABG}$ or establishment of AV fistula.

Early hemostasis control was immediately achieved within $12 \mathrm{~min}$ on average in DTRA compared to more than 15 minutes in CTRA regardless of the administered anticoagulation. Moreover, complete hemostasis was achieved in almost $3 \mathrm{~h}$ with a slightly compression bandage with gauze applied over the puncture site. As the distal radial artery passes over a bony basement, compression with the thumb over that area can lead to arterial occlusion. Hence, we decided to apply it just for $15 \mathrm{~min}$. No hematoma in the study population showed that the access site is safe in terms of hemorrhagic complications compare to CTRA and this is supported by other studies. ${ }^{8,12}$ The ease, safety and comfortability of this new radial approach should be kept in mind to prevent radial artery occlusion, radial artery spasm, and extended procedure times.

\section{Conclusion:}

Distal radial artery access technique is very much safe, effective, easy, comfortable and relatively free from major complications for coronary angiography and interventions compared to conventional transradial access. It merits consideration regarding proper patient selection, preparation, and equipment for successful transradial catheterization.

\section{Study limitations:}

Puncture of distal radial artery can be challenging as its diameter is smaller than the radial artery. Its access requires a steeper learning curve, especially when the pulse in AS is weak. We experienced difficulty in patients who had a prominent radial styloid process and a small AS area.We did not need to perform duplex 
ultrasonography in any patient as we found a normal pulse in the AS area in all while checking for hemostasis on the discharge day. Although, our study has only a small population group, it showed favorable results in terms of patient and operator comfortability, which was in concordance with other studies. ${ }^{8,12}$

\section{References:}

1. Mueller RL, Sanborn TA. The history of interventional cardiology; cardiac catheterization, angioplasty and related interventions. Am Heart J 1995; 129(1): 146-72.

2. Brueck M, Bandorski D, Kramer W, Wieczorek M, Höltgen R, Till-manns H. A randomized comparison of transradial versus trans-femoral approach for coronary angiography and angioplasty. JACC CardiovascInterv 2009; 2(11): 1047-54.

3. Cantor WJ, Puley G, Natarajan MK, Dzavik V, Madan M, Fry A, et al. Radial versus femoral access for emergent percutaneous coro-nary intervention with adjunct glycoprotein IIb/IIIa inhibition in acute myocardial infarction - the RADIAL-AMI pilot randomized trial. Am Heart J 2005; 150(3): 543-9.

4. Jolly SS, Yusuf S, Cairns J, Niemelä K, Xavier D, Widimsky P, et al; RIVAL trial group. Radial versus femoral access for coronary an-giography and intervention in patients with acute coronary syn-dromes (RIVAL): a randomized, parallel group, multicentre trial. Lancet 2011;377(9775): 1409-20.

5. Valgimigli M, Gagnor A, Calabró P, Frigoli E, Leonardi S, Zaro T, et al; MATRIX Investigators. Radial versus femoral access in patients with acute coronary syndromes undergoing invasive management: a randomized multicentre trial. Lancet 2015;385(9986): 2465-76.

6. Kiemeneij F, Laarman GJ, Odekerken D, Slagboom T, van der Wieken R. A randomized comparison of percutaneous transluminal coro-nary angioplasty by the radial, brachial and femoral approaches: the access study. J Am CollCardiol 1997; 29(6): 1269-75.

7. Agostoni P, Biondi-Zoccai GG, de Benedictis ML, Rigattieri S, Turri M, Anselmi M, et al. Radial versus femoral approach for percutane-ouscoronary diagnostic and interventional procedures; Systematic overview and meta-analysis of randomized trials. JAm Coll Cardiol 2004; 44(2): 349-56.

8. Kiemeneij F. Left distal transradial access in the anatomical snuff-box for coronary angiography (ldTRA) and interventions (ldTRI). Euro Intervention 2017; 13(7): 851-7.

9. Cerda A, Del Sol M. Anatomical snuffbox and it clinical significance. A literature review. Int J Morphol 2015; 33(4): 1355-60.

10. Doscher W, Viswanathan B, Stein T, Margolis IB. Hemodynamic as-sessment of the circulation in 200 normal hands. Ann Surg 1983; 198(2): 776-9.

11. Shah RM, Patel D, Abbate A, Cowley MJ, Jovin IS. Comparison of transradial coronary procedures via right radial versus left radial artery approach: A meta-analysis. Catheter CardiovascInterv 2016; 88(7): 1027-33.

12. Kaledin AL, Kochanov IN, Podmetin PS, Seletsky SS, Ardeev VN. Distal radial artery in endovascular interventions. Distal radial ar-tery in endovascular interventions(p.)2017. Unpublished.https:/ /doi.org/10.13140/rg.2.2.13406.33600

13. Tubbs RS, Salter EG, Oakes WJ. The tabatièreanatomique. ClinAnat. 2006; 19(4): 299-303.

14. Robson AJ, See MS, Ellis H. Applied anatomy of the superficial branch of the radial nerve. ClinAnat 2008; 21(1): 38-45.

15. Gupta S, Nathan S. Radial Artery Use and Reuse. Cardiac Interven-tions Today 2015; 49-56.

16. McLean KM, Sacks JM, Kuo YR, Wollstein R, Rubin JP, Lee WP. Anatomical landmarks to the superficial and deep palmar arches. PlastReconstrSurg 2008; 121(1): 181-5.

17. Loukas M, Holdman D, Holdman S. Anatomical variations of the su-perficial and deep palmar arches. Folia Morphol (Warsz) 2005; 64(2): 78-83.

18. Joshi SB, Vatsalaswamy P, Bahetee BH. Variation in formation of superficial palmar arches with clinical implications. J ClinDiagn Res 2014; 8(4): AC06-9. 